\title{
Prevalence of Co-existing dermatological manifestations in Cutaneous Leishmaniasis
}

\author{
Dinusha MGA ${ }^{1}$, Thushara, HKGI ${ }^{2}$, Rathnayaka RMUK ${ }^{3}$,Sudusinghe PWM ${ }^{4}$, Wijenayake BKS ${ }^{5}$ \\ ${ }^{1}$ Consultant Dermatologist, District General Hospital, Negombo, Sri Lanka \\ ${ }^{2}$ Medical Officer, District General Hospital, Matara, Sri Lanka \\ ${ }^{3}$ Deputy Director, District General Hospital, Matara, Sri Lanka \\ ${ }^{4}$ Medical Officer, District General Hospital, Matara, Sri Lanka \\ ${ }^{5}$ Consultant Dermatologist, Teaching Hospital, Karapitiya, Sri Lanka
}

Corresponding Author: MGA Dinusha, Consultant Dermatologist, District General Hospital, Negombo, Sri Lanka

Email: asanthidgamage@gmail.com

iD https://orcid.org/0000-0001-6393-7499

\begin{abstract}
Introduction

Leishmaniasis is a vector borne protozoan infestation and manifested as cutaneous, visceral and muco-cutaneous lesions in human. Visceral form is the most virulent type and the annual incidence was 0.2-0.4 million cases around the world. ${ }^{1}$ But, in Sri Lanka, Cutaneous Leishmaniasis (CL) is a newly established disease and is emerging as a threat to public health. ${ }^{2}$ In Sri Lanka the condition is still not fully investigated nor well studied.
\end{abstract}

\section{Method}

The aim of this descriptive cross-sectional study was to determine the prevalence of $\mathrm{CL}$ in the patients coming to the dermatology unit and clinic of the District General Hospital, Matara, Sri Lanka. The study was conducted from August 2016 to March 2017.

\section{Results}

There were 129 participants subjected to Leishmanin Skin Test accompanied with direct interviews and physical examination. The most of participants were males $(52.8 \%), 68.4 \%$ of them unskilled. The highest prevalent type was Non scaly nodule (45.0\%). Most common site of lesion was arm (47.1\%). Majority had a single lesion (76.7\%). Co-existing skin manifestations of hypopigmentation (36.9\%) was the commonest. In (63.6\%), co-existing skin lesions involved only less than $2 \%$ of body surface area. The hypopigmentation was significantly associated with Age, Sex and work outdoor while photodermatitis was significantlyassociated with age and photosensitivity. Eczematisation was significantly associated with diabetes mellitus and hyperlipidaemia.

\section{Conclusions}

Cutaneous Leishmaniasis is more prevalent among 31 -41-year age group and males. Majority are primary, single, early presentationandnon-scaly nodule. The limbs are the commonest affected site. 
$\mathrm{CL}$ is significantly associated with co-existing skin manifestations of hypopigmentation, photodermatitis, eczematisation and follicular papules.

Keywords:Cutaneous Leishmaniasis, hypopigmentation, photodermatitis, eczematisation, Sri Lanka.

\section{Introduction}

Leishmaniasis is a vector borne protozoan infestation and it is manifested as cutaneous, visceral and muco-cutaneous lesions in human. Visceral form is the most virulent type and the annual incidence is 0.2-0.4 million cases around the world. Majority (90\%) is reported from India, Bangladesh, Nepal, Sudan, Ethiopia and Brazil. The most common manifestation is cutaneous lesions and it is prevalent in Afghanistan, Algeria, Iran, Saudi Arabia, Syria, Brazil, Colombia, Peru and Bolivia. Annual incidence is around $0.7-1.2$ million globally. In addition, it is found recently in Mexico, Central America, South America and United States of America ${ }^{1}$.

In Sri Lanka, $\mathrm{CL}$ is a newly established disease and is emerging as a threat to public health. It was considered as exotic disease and cases were limited to Middle East returnees. But in 1992 the first case of locally acquired patient was found in Ambalantota and the second case was found in 1995 in Mahiyanganaya. Until year 2000, cases were sporadic in many districts of Sri Lanka. Now the cases are increasing in number mostly in Anuradhapura, Polonnaruwa, Hambantota and Matara districts. Maximum number of 2000 cases were reported in year 2008 and 940 cases were reported in 2011. Causative variety was identified as Leishmania donovani MON-37 in 2002. This strain differs from the Leishmania donovani MON-2 which causes visceral Leishmaniasis in India. Visceral Leishmaniasis is rare in Sri Lanka, with 4 cases have been reported so far. The first case was reported in 2006 from Anuradhapura².

$\mathrm{CL}$ is transmitted by sand-fly called phlebotomus argentipes. Initially it was thought that transmission is autochthonous but in 2009 it was found dog as a reservoir in Sri Lanka. ${ }^{3}$ To minimize the disease burden in Sri Lanka, it is important to identify patients by the clinicians who are not only working in the dermatology clinics, also in other units like dental, medical and ear-nose-throat clinics. Diverse clinical presentations ranging from acne-form papules to complicated ulcers are challenging to clinicians. Associations of coexisting dermatological conditions, further complicate the accurate diagnosis.

Polymorphic presentations of CLhave become more prevalent in many parts of the country.Sometimes, Co-existing manifestation is the first clinical presentation of the disease.

$\mathrm{CL}$ usually present as papules, nodules or non-healing ulcers. But different morphological presentations and coexisting manifestations could mimic various skin disorders. This can delay the diagnosis of the disease. A study conducted in Punjab; Pakistan has revealed $5.7 \%$ of unusual presentations of the disease. ${ }^{4}$ Majority of them presented as lupoid lesions (13 cases, $34 \%$ ), sporotrichoid (12\%) and paronychia (7.3\%). In a case series studydone in Muzaffarabadhas revealed lesions resembling lupus vulgaris or lupus erythematosus on the face or elsewhere and was included in the study $y^{5}$. Such variations in the clinical and pathological presentations may be due to differences either in the host's immunologic reactivity or species-specific activity.Five Iranian females have shown infiltrative erythematous lesions of CLcovering the centre of the face and resembling erysipelas ${ }^{6}$. Similar case of erysipeloid form been reported from Tunisia ${ }^{7}$. Ethiopian case study they described about 2 patients with unusual presentations of diffuse CLpresenting with large hypopigmented skin lesions mimicking borderline-tuberculoid leprosy. ${ }^{9}$ 
Rare presentationsof eczematisation were reported in many studies. ${ }^{10,11}$ Rare presentation of nonhealing ulcer over a lip in an Italian man who left the country 19-year back was diagnosed as Leishmaniasis. ${ }^{2}$ HIV-Leishmania co-infection has caused unusual presentations and different treatment responses in India. ${ }^{13,14,15}$

Recent study done in Sri Lanka revealed variety of atypical lesions of $\mathrm{CL}$ and their clinical profile and treatment outcome. ${ }^{8}$

This study was planned tohelp in identifying demographic correlates, common co-existing skin manifestations of $\mathrm{CL}$ and their prevalence as well as correlations between severity of primary lesions and other co-existing manifestations. ${ }^{3}$

Another aim was to identify the correlations between clinical response to medications and behaviour of the photosensitivity reactions.

\section{Methods}

This wasa hospital-based, descriptive cross-sectional study which was carried out in Dermatology unit and clinic, at District General Hospital, Matara, Sri Lanka.

All cytological or histologically confirmed patients with $\mathrm{CL}$ who attended to Dermatology unit, DGH Matarafrom August 2016 to March 2017 were recruited except for patients with past history of photosensitivity, genetically predisposed patients for photosensitivity, patients with other skin disorders which could lead to id reactions, patients with atopic dermatitis or other pre-existing skin disease which could result in generalized eczema or exfoliative dermatitis, severely ill patients and children below 5 years of age were excluded from study.

The participation was entirely on a voluntary basis and informed consent was obtained from the study participants prior to data collection.

Ethical clearance was obtained from the Ethical Review Committee of the Faculty of Medicine, University of Ruhuna. The questionnaire was pre tested and validated at Teaching Hospital, Karapitiya. Interviewer administered questionnaires and data record sheets were used to collect data. The questionnaire consisted of three parts, Socio-demographic characteristics of the participants, Clinical history, Clinical presentation and observation.Each questionnaire consistedof close ended questions includingsociodemographic data, observation findings of lesions, parametric data on lesions and outcome assessment of lesions.

Outcome variables were different types of co-existing dermatological manifestations. Presence of hyper or hypopigmentation around primary lesion, other cutaneous features like photosensitive lesions and interface dermatitis with its morphological subtype, exfoliative dermatitis, surrounding eczematisation, erysipeloid and lupoid lesions were assessed clinically with their extent of involvement which was calculated according to rule of nine body surface area (BSA).Also, primary lesion was photographed with a scale in centimetres and processed in AutoCAD software to obtain the accurate measurement and size of primary skin lesion.

Results

\section{Socio Demographic Characteristics}

The total of 129 patients were enrolled in this study. Table 1 shows the distribution of selected socio-demographic characteristics among respondents. 
Table 01: Socio Demographic Characteristics

\begin{tabular}{|c|c|c|c|c|c|}
\hline \multirow[t]{2}{*}{ Age group } & \multirow{2}{*}{$\begin{array}{l}\text { Number } \\
\text { (percenta } \\
\text { ge) }\end{array}$} & \multicolumn{2}{|c|}{$\begin{array}{l}\text { Sex Number } \\
\text { (percentage) }\end{array}$} & \multirow{3}{*}{$\begin{array}{l}\text { Occupation } \\
\text { Unskilled } \\
\text { Skilled }\end{array}$} & \multirow{2}{*}{$\begin{array}{r}\begin{array}{r}\text { Number } \\
\text { (percentage) }\end{array} \\
89(68.4)\end{array}$} \\
\hline & & Male & $68(52.8)$ & & \\
\hline $0-10$ & $14(10.9)$ & & & & $32(24.5)$ \\
\hline $10-20$ & 18 (13.9) & Female & $61(47.2)$ & Professional & $8(6.1)$ \\
\hline $21-30$ & $7(5.4)$ & Total & $129(100)$ & Total & $129(100)$ \\
\hline $31-40$ & $33(25.6)$ & & & & \\
\hline $41-50$ & $24(18.6)$ & & & & \\
\hline $51-60$ & $18(14.0)$ & & & & \\
\hline $61-80$ & 15 (11.6) & & & & \\
\hline Total & $129(100)$ & & & & \\
\hline
\end{tabular}

Age range was between 06 years and 78 years (Mean age $=42$ years, SD=18years). The age group 3140 years was the most prevalent (25.6\%) age group in $\mathrm{CL}$ whereas $10.9 \%$ of patients were less than 10 years of age.

$52.8 \%$ of study population were males.

In addition to the above variables, $68.4 \%$ were in unskilled occupations while only were $6.1 \%$ professional.

\section{Clinical Profile}

44.9\% patients had presented to the dermatology specialized clinic within first 4 weeks of onset of primary skin lesion of $\mathrm{CL}$ followed by $42.5 \%$ presented between 4 and 8 weeks.No one had symptoms of more than 24 weeks.

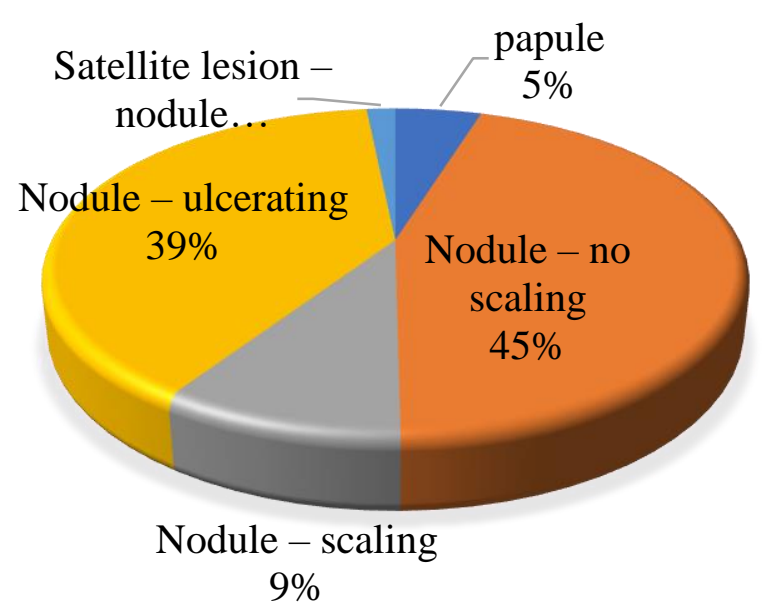

\section{Chart.01 Type of primary skin lesion}

The commonest type of $\mathrm{CL}$ was Non scaly nodule (45.0\%). 39.0\% lesions were ulcerated nodules. 

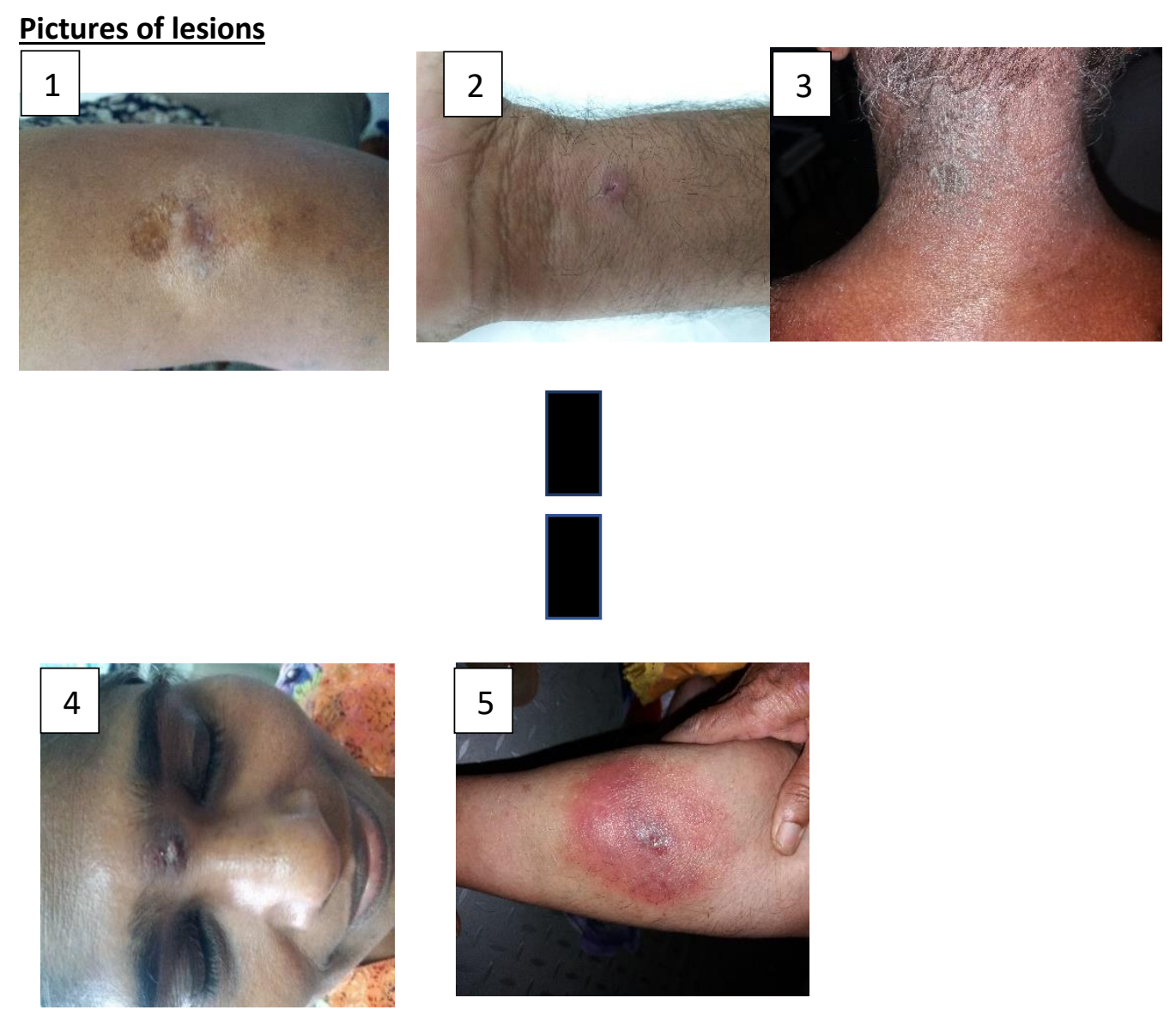

Picture 1. Hypopigmentation around primary lesion, 2. Non scaly non- ulcerated nodule, 3 . Severe photodermatitis in a patient with $\mathrm{CL}, 4$. Ulcerated nodule on face, 5 . Erysipelas like eruption around a lesion of $\mathrm{CL}$.

Table. 02 Site of primary lesion

\begin{tabular}{lc}
\hline Site & Number (percentage) \\
\hline Head/ face and neck & $37(19.6)$ \\
Chest & $15(7.9)$ \\
Abdomen & $3(1.6)$ \\
Upper limb & $\mathbf{8 9 ( 4 7 . 1 )}$ \\
Lower limb & $45(23.8)$ \\
\hline Total & $\mathbf{1 8 9 ( 1 0 0 )}$ \\
\hline
\end{tabular}

Note: Total is more than 129 as there are more than one lesion in some patients

Many patients had primary skin lesion on Upper limbs (47.1\%).

Majority of patients had only one lesion (76.7\%). The $10.1 \%$ and $7.0 \%$ had 2 and 3 lesions respectively. Patients and 5 or 6 lesions were $1.6 \%$ each. None of the participants had more than 6 lesions. 
Table.03 Size of primary skin lesion

\begin{tabular}{lr}
\hline Co-morbidity & \multicolumn{1}{c}{$\begin{array}{l}\text { Number } \\
\text { (percentage) }\end{array}$} \\
\hline HPT & $\mathbf{2 8 ( 2 1 . 7 )}$ \\
DM & $22(17.1)$ \\
Hyperlipidaemia & $17(13.1)$ \\
BA & $2(1.5)$ \\
IHD & $3(2.3)$ \\
Hypothyroidism & $3(2.4)$ \\
None & $\mathbf{8 7}(\mathbf{6 7 . 4 )}$ \\
\hline Total & $\mathbf{1 2 9 ( 1 0 0 )}$ \\
\hline
\end{tabular}

Majority (27.6\%) of primary lesions were between $1.1 \mathrm{~cm} 2$ and $2 \mathrm{~cm} 2$ followed by $2.1 \mathrm{~cm} 2-3 \mathrm{~cm} 2$. (24.0\%).

Table.04 Associated Co-morbidities

\begin{tabular}{lr}
\hline Size of all lesions & Number (percentage) \\
\hline $0.0-1.0$ & $29(15.1)$ \\
$\mathbf{1 . 1}-\mathbf{2 . 0}$ & $\mathbf{5 3 ( 2 7 . 6 )}$ \\
$2.1-3.0$ & $46(24.0)$ \\
$3.1-4.0$ & $30(15.6)$ \\
$4.1-5.0$ & $16(8.3)$ \\
5.1 or above & $18(9.4)$ \\
\hline Total & $\mathbf{1 2 9 ( 1 0 0 )}$ \\
\hline
\end{tabular}

Majority (67.4\%) didn't have any co-morbidities. $21.7 .0 \%$ patients of $\mathrm{CL}$ in the study were diagnosed to have hypertension which was the most prevalent comorbid factor followed by diabetes mellitus (17.1\%) and hyperlipidaemia (13.1\%).

None of the patient in our study had any type of systemic manifestations of Visceral Leishmaniasis

Table.05. Site of Co-existing skin manifestations (related to primary skin lesion) out of patients who had Co-existing skin manifestations

\begin{tabular}{lc}
\hline $\begin{array}{l}\text { Site of Co-existing skin } \\
\text { manifestations }\end{array}$ & Number (percentage) \\
\hline Local (around primary lesion) & $\mathbf{5 9 ( 4 5 . 7 )}$ \\
Distant & $7(5.4)$ \\
Both Local and Distant & $24(18.6)$ \\
None & $54(69.7)$ \\
\hline Total & $\mathbf{1 2 9 ( 1 0 0 )}$ \\
\hline
\end{tabular}

There were $69.7 \%$ of patients with primary CL were found to have one or multiple other cutaneous co-existing skin lesions in addition to the primary lesion. $45.7 \%$ patients had co-existing lesions only locally (around primary site) where as $5.4 \%$ had those skin lesions only in distant sites of the body. Both local and distant co-existing skin lesions were seen in $18.6 \%$ patients. 
Table.06Co-existing skin manifestations

\begin{tabular}{lr}
\hline \multicolumn{1}{c}{$\begin{array}{c}\text { Type of Co-existing skin } \\
\text { manifestations }\end{array}$} & \multicolumn{1}{c}{$\begin{array}{l}\text { Number } \\
\text { (percentage) }\end{array}$} \\
\hline Hypopigmentation & $\mathbf{4 1 ( 3 6 . 9 )}$ \\
Hyperpigmentation & $9(8.1)$ \\
Photodermatitis & $21(18.9)$ \\
Follicular papules & $13(11.7)$ \\
Macular- popular eruption & $1(0.9)$ \\
Papulo- vesicular eruption & $1(0.9)$ \\
Pompholyx like eruption & $1(0.9)$ \\
Erysipelas like eruption & $2(1.8)$ \\
Eczematisation & $12(10.8)$ \\
Erysipeloid & $10(9.0)$ \\
\hline Total & $\mathbf{1 1 1 ( 1 0 0 )}$ \\
\hline
\end{tabular}

Note: some does not have co-existing lesions and some have more than one.

The commonest type of co-existing skin manifestation was hypopigmentation (36.9\%) mainly around the primary skin lesion/s. Secondly, Photodermatitis followed by follicular papules and eczematisation (local, distant or both) with the percentages of $18.9 \%, 11.7 \%$ and $10.8 \%$ respectively.

Furthermore,63.6\% of co-existing skin lesions involved only less than $2 \%$ of Body Surface Area (BSA). $2.1 \%-4 \%$ BSA involvement was seen in $9.9 \%$ of co-existing lesions while $10.8 \%$ had $4.1 \%-6 \%$ BSA involvement. Only $1.8 \%$ of co-existing skin lesions extended more than $10 \%$ BSA.

Table.07 Binary logistic regression was used to evaluate the association between factors and $P$ values of co-existing lesions

\begin{tabular}{lccc}
\hline Factors & $\begin{array}{c}\text { Hypopigmentatio } \\
\mathbf{n}\end{array}$ & $\begin{array}{c}\text { Hyperpigmentatio } \\
\mathbf{n}\end{array}$ & $\begin{array}{c}\text { Photodermatit } \\
\text { is }\end{array}$ \\
\hline Age & $\mathbf{0 . 0 0 8}$ & 0.722 & $\mathbf{0 . 0 5 0}$ \\
Sex & $\mathbf{0 . 0 4 4}$ & 0.899 & 0.154 \\
Occupation & 0.991 & 0.993 & 0.996 \\
Duration PL & 1.000 & 1.000 & 1.000 \\
Size of PL & 1.000 & 1.000 & 1.000 \\
Number of PL & 0.112 & 0.993 & 0.369 \\
Co-morbidities HTN & 0.521 & 0.260 & 0.055 \\
Co-morbidities DM & 0.691 & 0.994 & 0.341 \\
Co-morbidities Hyperlipidaemia & 0.989 & 0.660 & 0.576 \\
Co-morbidities BA & 0.841 & 0.993 & 0.315 \\
Co-morbidities IHD & 0.841 & 0.124 & 0.993 \\
Co-morbidities hypothyroidism & 0.992 & 0.993 & 0.993 \\
Predisposing factors drugs & 0.870 & 0.993 & 0.993 \\
Occupation at outdoor & $\mathbf{0 . 0 1 4}$ & 0.473 & 0.004 \\
Occupation at indoor & 0.101 & 0.351 & 0.668 \\
Outdoor without cloths & 0.065 & 0.730 & 0.107 \\
Photosensitivity & & & 0.010 \\
Leishmaniasis & 0.991 & 0.078 & 0.541 \\
& 0.991 & & \\
\hline
\end{tabular}


The hypopigmentation was significantly associated with age, sex and work at outdoor while photodermatitis was associated significantly with age, and photosensitivity at $95 \%$ confidence level.

Table.08 Binary logistic regression was used to evaluate the association between predisposing factors and $P$ values of co-existing lesions

\begin{tabular}{lccc}
\hline Factors & Follicular papules & Eczematisation & Erysipeloid \\
\hline Age & 0.309 & 0.524 & 0.384 \\
Sex & 0.351 & 0.413 & 0.994 \\
Occupation & 0.995 & 0.995 & 0.998 \\
Duration PL & 1.000 & 1.000 & 1.000 \\
Size of PL & 1.000 & 1.000 & 1.000 \\
Number of PL & 0.061 & 0.384 & 0.087 \\
Co-morbidities HTN & 0.687 & 0.157 & 0.416 \\
Co-morbidities DM & 0.958 & 0.007 & 0.995 \\
Co-morbidities Hyperlipidaemia & 0.817 & 0.014 & 0.993 \\
Co-morbidities BA & 0.996 & 0.993 & 0.993 \\
Co-morbidities IHD & 0.996 & 0.993 & 0.993 \\
Co-morbidities hypothyroidism & 0.996 & 0.993 & 0.993 \\
Drugs & 0.996 & 0.993 & 0.993 \\
Occupation outdoor & 0.979 & 0.223 & 0.582 \\
Occupation indoor & 0.179 & 0.071 & 0.626 \\
Outdoor without cloths & 0.994 & 0.823 & 0.402 \\
Photosensitivity & 0.995 & 0.992 & 0.995 \\
Leishmaniasis & 0.081 & 0.995 & 0.995 \\
\hline
\end{tabular}

This shows Eczematisation was significantly associated with diabetes mellitus and hyperlipidaemia at $95 \%$ confidence level.

\section{Discussion and Conclusions}

Age and gender association of $\mathrm{CL}$ were constant with previous findings of studies in the country. ${ }^{8}$ Although he commonest age group was $21-30$ years in this sample CL was most prevalent among youngsters, below 20 years. In Sri Lanka 21 - 30 age group people engage in moreoutdoor activities than children, household clustering and peri domestic transmission could be causing this difference. Non scaly nodule was the commonest presentation (45.0\%) in this study which is nearly similar to the past findings in Sri Lanka whereas the ulcerative nodule was the commonest type of $\mathrm{CL}$ in Pakistan and Brazil. This may be due to difference of species. Many patients have presented before 4 weeks from the onset of skin lesion/s (44.9\%) which is somewhat earlier than previous studies. Raising awareness among general public regarding the condition leading to enhance self-referrals is the probable reason for this early presentation.

76.7\% of participants of our study had had only single primary lesion of CL which is slightly lesser than recent findings of other local studies. ${ }^{8}$

Limbs (Upper limbs > Lower limbs) are the commonest sites for primary skin lesions in our study. The percentages are nearly similar to the other studies done locally and south Asian continent ${ }^{8}$. $58 \%$ of patients in this study had either one or multiple comorbidities in which the hypertension was the commonest followed by diabetes mellitus. Further, analysis revealed eczematisation was more prevalent among patient with diabetes mellitus. 
$27.4 \%$ of skin lesions were between $1.1-2.0 \mathrm{~cm}^{2}$ followed by $20.0 \%$ of $21-3.0 \mathrm{~cm}^{2}$. Altogether these two is closely similar to the findings for the size of primary skin lesions in India.

Outdoor activities were the most prevalent predisposing factor for $\mathrm{CL}$ in both local $\mathrm{s}$ well as international setting. Similarly, we found the same factor predisposed to cause co-existing other skin manifestations of $\mathrm{CL}(69.0 \%)$.

Even though many patients presented with primary skin lesion of $\mathrm{CL}$, some patients presented with other nonclassical lesions such as photodermatitis, id reactions, follicular papules of eczematised reactions in which examination revealed primary lesion.

The prevalence these co-existing skin manifestations were not described in detail inpreviousstudies. Development of more treatment resistant virulent strains of Leishmania Donovan organism might be causing more severe immune response of $\mathrm{CL}$, could be responsible for this recent appearance of other co-existing skin manifestations.

Analysis revealed both hypopigmentation and photodermatitis decreases when age increases. Reduced outdoor activities in old population could be causing this.

Moreover, hypopigmentation was less among patient with outdoor activities.

Besides, Photodermatitis was more prevalent on patients who had past history of photodermatitis. utaneous Leishmaniasis is more prevalent in $31-41$ years and male sex. Majority had presented very early to the dermatology.

Single and Non-scaly nodule mainly on limbs was the commonest presentation. Although majority didn't have comorbidities, eczematisation was more prevalent on patients with diabetes mellitus. Primary disease was common among people without-door based occupations.

Significant proportion of patients with $\mathrm{CL}$ had other co-existing skin manifestations which are mainly hypopigmentation, photodermatitis, eczematisation and follicular papules.

\section{Recommendations}

Being a very common skin disease establishment of more disease awareness programmes regarding domestic prevention and mass preventive programmes among general public are recommended in order to reduce the burden of the disease.

Rising cases of co-existing other skin manifestations in $\mathrm{CL}$ will need more research to find out the immunological basis / pathogenesis of these manifestations.

Teaching programmes are recommended to medical professionals to identify the primary lesion when patients presented with other co-existing skin manifestations in early stage of disease and make tertiary care referral and notification to prevent delaying of treatment. 


\section{References}

1. World Health Organization, 2010. Technical Report Series. Control of the Leishmaniasis, Geneva, Switzerland. Pp: 1-4.

2. Epidemiology Unit Ministry of Health Sri Lanka, 2012. Leishmaniasis Fact Sheet. Pp: 2, 3.

3. Epidemiology unit Ministry of Health, Nutrition \& Indigenous medicine,2019. Weekly epidemiological report a publication, 2019 of February Vol. 46 No. 08. Pp: 1-2).

4. Bari A, Rahman SB, 2008. Many faces of cutaneous leishmaniasis. Indian J Dermatol Venereol. Pp: 74:23.

5. Ul Bari A, Raza N, 2010. Lupoid cutaneous leishmaniasis: a report of 16 cases. Indian J Dermatol VenereolLeprol.76(1). Pp:85.

6. Salmanpour R, Handjani F, Zerehsaz F, Ardehali S, Panjehshahin MR, 1999. Erysipeloid leishmaniasis: an unusual clinical presentation. Eur J Dermatol. 1999Sep; 9(6). Pp: 458-9.

7. Mnejja M, Hammami B, Chakroun A, Achour I, Charfeddine I, Chakroun A, TurkiH, Ghorbel A, 2011. Unusual form of cutaneous leishmaniasis: erysipeloid formApr;128(2). Pp:95-7

8. Sriwardana Y, Deepachandi B, Gunasekara C, Warnakulasooriya W, Karunaweera N D, 2019. Leishmania donovani induced Cutaneous Leishmaniasis - An Insight into Atypical variations in Sri Lanka; Hindawi Journal of Tropical Medicine;Volume 2019;Article. Pp:11.

9. Dassoni F, Abebe Z, Naafs B, Morrone A, 2013. Cutaneous and mucocutaneous leishmaniasis resembling borderline-tuberculoid leprosy: a new clinicalpresentation? Acta DermVenereolJan;93(1). Pp:74-7.

10. Ayatollahi J, FattahiBafghi A, Shahcheraghi SH, 2014. Rare variants of cutaneous Leishmaniasis presenting as eczematous lesions. Med J Islam Repub Iran. 2014 Jul 21. Pp; 28:71.

11. Ramot Y, Nanova K, Alper-Pinus R, Zlotogorski A, 2014. Zosteriform cutaneous leishmaniasis diagnosed with the help of dermoscopy. Dermatol Pract Concept. 2014Jul 31;4(3). Pp:55-7.

12. Crowe A, Slavin J, Stark D, Aboltins C. A, 2014.Case of imported Leishmania infantum cutaneous leishmaniasis; an unusual presentation occurring 19 years after travel.BMC Infect Dis. 2014 Nov 27. Pp; 14

13. Singh $S, 2014$. Changing trends in the epidemiology, clinical presentation, anddiagnosis of Leishmania-HIV co-infection in India. Int J Infect Dis. 2014Dec. Pp;29:103-12.

14. Montenegro-Idrogo JJ, Montañez-Valverde RA, Chian C, Benites-Villafane C, 2014.Mucocutaneous leishmaniasis in a HIV infected patient. Case report. Rev Chilenalnfectol. 2014 Oct;31(5). Pp :610-4.

15. Badaró R, Gonçalves LO, Gois LL, Maia ZP, Benson C, Grassi MF, 2015. Leishmaniasisas a Manifestation of Immune Reconstitution Inflammatory Syndrome (IRIS) in HIV-Infected Patients: A Literature Review. J Int AssocProvid AIDS Care. 2015Sep-Oct; 14(5). Pp:402-7. 